\title{
Method to predict and optimise charge sensitivity of ungated AlGaN/GaN HEMT-based ion sensor without use of reference electrode
}

\author{
Anna Podolska, Daniel Broxtermann, Joerg Malindretos, Gilberto A. Umana-Membreno, Member, \\ IEEE, Stacia Keller, Umesh K. Mishra, Fellow, IEEE, Angela Rizzi, Brett D. Nener, Senior Member, \\ IEEE, and Giacinta Parish, Member, IEEE
}

\begin{abstract}
In this paper we report on a methodology for theoretical prediction and optimization of charge sensitivity for ungated AlGaN/GaN HEMT-based ion sensors operated in reference electrode free configuration. We have performed numerical simulations of device sensitivity, specifically the change in channel electron concentration with the change in surface potential, for different $\mathrm{Al}$ mole fractions and AlGaN thicknesses. These results can be used for device optimization, signal analysis and sensor calibration purposes. To validate the model, six ungated AlGaN/GaN transistor-based devices of different Al mole fraction and AlGaN thickness were fabricated. These devices were exposed to $\mathrm{KOH}$ solutions with different $\mathrm{pH}$ values, and the voltage change at the gate area was indirectly measured as a function of ionic concentration. The gain in conductivity across the measured range of $\mathrm{pH}$ values was experimentally extracted for each device and closely matched the sensitivity predicted by simulation.
\end{abstract}

Index Terms—sensors, HEMT, AIGaN/GaN, ISFET, sensitivity

\section{INTRODUCTION}

A LGAN/GAN heterostructures are showing promise for the development of chemical and biochemical sensors for a variety of applications in industrial process monitoring, pharmaceutical and medical research and product development [1], [2], [3], [4]. The potential of AlGaN/GaN heterojunctionbased devices for chemical sensing stems from several factors: they are stable in harsh environments and have low toxicity, their conductivity is strongly affected by surface conditions, and ungated surfaces are amenable to functionalization [5]. For AlGaN/GaN grown along the [0001] axis with $\mathrm{Ga} / \mathrm{Al}$-polarity the strong spontaneous as well as piezoelectric polarization of

Submitted for review on 3 November 2014. Revisions submitted for review on 11 February 2015 and 28 April 2015. This work has been supported by the William and Marlene Schrader Trust, the Australian Research Council Discovery Project scheme, the Western Australian Node of the Australian National Fabrication Facility, the Office of Science of the WA State Government, the Group of Eight Australia-Germany Joint Research Cooperation Scheme and ONR-MURI supervised by P. Maki and H. Dietrich.

A. Podolska was with the School of Electrical, Electronic and Computer Engineering, The University of Western Australia, Crawley, WA 6009 Australia. She is now with the Department of Exploration Geophysics, Curtin University, Kensington, WA 6151 Australia (email: anna.podolska@curtin.edu.au). the strained AlGaN top layer results in the formation of a twodimensional electron gas (2DEG) in the narrower band gap GaN side of the heterojunction [6]. This 2DEG acts as a highly conductive channel for Field Effect Transistor (FET)-type devices that can be modulated by changes in the surface potential. Thus, devices without gate metallization can be used to directly sense charged particles and adsorbed molecules [6], [7], [8], [9], [10], [11]. The realisation of reference electrode free measurements permits the fabrication of small, robust and on-chip AlGaN/GaN FET-based sensors, providing a clear advantage over existing glass electrode based $\mathrm{pH}$ and ion sensors. Although reference-electrode free $\mathrm{pH}$ sensing has been demonstrated [12],[13], the scope of the reported investigations has been limited in terms of reference electrode free sensor optimisation. Ion sensitivity in reference electrode free sensors has been shown to depend on AlGaN/GaN composition [14], which is not surprising given that the heterostructure design determines sheet carrier density. While carrier charge density and mobility have been theoretical calculated for various AlGaN/GaN FET structures in the context of transistor operation, and to a limited extent to explain the behaviour of ungated $\mathrm{AlGaN} / \mathrm{GaN}$ FET sensors[15], such calculations have yet to be systematically deployed to investigate the sensitivity limits of reference electrode free sensors, and/or to determine design parameters for practical sensor optimisation.

The sensitivity of $\mathrm{AlGaN} / \mathrm{GaN} \mathrm{pH}$ sensors is often quantified as the change in gate voltage $\left(\mathrm{V}_{\mathrm{G}}\right)$ in $\mathrm{mV}$ per $\mathrm{pH}$, with the extracted value being then compared to the theoretical Nernstian response $(59.9 \mathrm{mV} / \mathrm{pH}$ at room temperature). In sensor applications in which a reference electrode can be employed, the sensor can be tuned to its maximum sensitivity

D. Broxtermann was with the IV. Physikalisches Institut, Georg-August Universität Göttingen , Göttingen, He is now with Infineon, Germany.

J. Malindretos and A. Rizzi are with the IV. Physikalisches Institut, GeorgAugust Universität Göttingen, Göttingen, D-37077 Germany.

G.A. Umana-Membreno, B.D. Nener and G. Parish are with the National Institute of Standards and Technology, Boulder, CO 80305 USA (e-mail: giacinta.parish@uwa.edu.au).

S. Keller and U.K. Mishra are with the . Department of Electrical and Computer Engineering, University of California, Santa Barbara, CA 93106 USA. 
by biasing the device to its maximum transconductance $\left(\mathrm{g}_{\mathrm{m}}\right)$. Evidently, this approach relies on the reference electrode to maintain and/or manipulate the gate potential. However, $\mathrm{V}_{\mathrm{G}}$ cannot be measured nor manipulated without a reference electrode in ungated sensor devices. Reference-electrode free devices require a different approach, and device sensitivity in terms of induced surface potential needs to be extracted from $\mathrm{I}_{\mathrm{DS}}$ or $\mathrm{V}_{\mathrm{DS}}$ often employing simplifying approximations [16], [17]. In terms of heterostructure design, Brazzini et al. recently demonstrated AlInN/GaN-based sensors with high sensitivity even when employed in reference electrode free measurement configuration [13]. In their study, which included measurements with and without reference electrodes, devices fabricated employing thinner AlInN layers demonstrated better sensitivity compared to sensors with thicker AlInN layer when measured without a reference electrode. In this work, experimental results and theoretical calculations demonstrate that barrier composition and barrier thickness need to be optimised together to obtain highly sensitive AlGaN/GaN heterostructure-based sensors in a reference electrode free configuration for ion and $\mathrm{pH}$ sensing applications.

\section{MATERIALS AND METHODS}

\section{A. Theoretical Modelling of Sensitivity}

The exposure of Ga-face AlGaN/GaN layers to ionic solutions leads to a shift of the surface potential toward a more negative value and thus to a change in the sheet carrier density and mobility $\left(\Delta \mathrm{n}_{\mathrm{s}}\right.$ and $\left.\Delta \mu\right)$ of the 2DEG. Such an influence on the 2DEG can be compared to an effective gate voltage $\left(\mathrm{V}_{\mathrm{G}, \mathrm{eff}}\right)$ applied to the active area of the device. It is known that the change in 2DEG parameters is maximal near the threshold voltage for any AlGaN/GaN device; this change will result in the maximum gain in the measured conductivity and therefore lead to very high sensitivity of the device. Most chemical and biological compounds should shift the surface potential of the reference-electrode-free device only by tens or hundreds of $\mathrm{mV}$ from initial zero volts bias (shifting by $59.9 \mathrm{mV} / \mathrm{pH}$ according to the Nernstian equation). Therefore the most sensitive reference-electrode-free devices will be obtained for near zero threshold voltage.

The experimentally measured gain in the conductivity is a product of sheet carrier density and mobility. The conductivity is the most useful and the most direct way of expressing and predicting sensitivity due to the direct relationship with measured current and inverse relationship with measured voltage. The change in measured current is directly proportional to the change in conductivity. Our aim was to predict an experimental gain in conductivity via modelling. This model can then be used for signal analysis and calibration. Although changes in mobility $(\Delta \mu)$ depend on the interplay of different scattering contributions and vary with device structure and material quality, mobility data can be found in the literature and utilized in the model [18]. To demonstrate this we obtained values of mobility variation with $\mathrm{V}_{\mathrm{G}}$ from the work of Asgari et al., one of the most sophisticated models for 2DEG density and mobility variation [18]. Four of the eight different AlGaN/GaN structures in Asgari et al.'s paper were selected (Table I) and changes in $n_{s}$ and threshold voltage were calculated for all four structures using a self-consistent 1D-Poisson solver [19]. Surface charge (modelled via $\mathrm{V}_{\mathrm{G} \text {,eff }}$ ) was varied for both mobility and carrier concentration $\left(\mathrm{n}_{\mathrm{s}}\right.$ and $\left.\mu\right)$ in the range from $-5 \mathrm{~V}$ to $1 \mathrm{~V}$ with $1 \mathrm{~V}$ step and by specifying appropriate boundary conditions with surface pinning of $-1.2 \mathrm{eV}$. There are a wide range of $\mathrm{AlGaN} / \mathrm{GaN}$ surface pinning values reported in the literature. The actual value is strongly dependent on heterostructure growth conditions and device processing steps. Therefore in the model the value was chosen to best match 1DPoisson simulations to carrier concentration obtained experimentally via Hall measurements. For a realistic figure of merit the change in $n_{s}$ and $\mu$ was normalized to the overall carrier concentration and mobility including the contribution from the bulk. The gain was calculated separately for $n_{s}, \mu$ and conductivity $(\sigma)$ according to

$$
\text { Gain=20 log }(\mathrm{K})[\mathrm{dB}]
$$

where $\mathrm{K}$ represents a relative change one of the three different 2DEG parameters $\mathrm{K}_{\mathrm{ns}}=\frac{\Delta \mathrm{n}_{\mathrm{s}}}{\mathrm{n}_{\mathrm{s}}} ; \mathrm{K}_{\mu}=\frac{\Delta \mu}{\mu} ; \mathrm{K}_{\sigma}=\frac{\Delta \sigma}{\sigma}$, which are related by $\mathrm{K}_{\sigma}=\mathrm{f}\left(\mathrm{K}_{\mathrm{ns}} ; \mathrm{K}_{\mu}\right)$. The conductivity was calculated from the carrier concentration and mobility according to

$$
\sigma=\mathrm{qn}_{\mathrm{s}} \mu(\mathrm{W} / \mathrm{L})
$$

where $\mathrm{q}=1.6 \times 10^{-19}$ is electron charge, $\mathrm{W}$ is width and $\mathrm{L}$ is length of the device.

Finally the gain in sheet carrier concentration was calculated using a self-consistent 1D-Poisson solver for a much wider range of structures. Such calculations allow modelling of device sensitivity as a function of AlGaN thickness and composition in any region of transistor characteristic. However, due to the nature of reference-electrode-free measurements for $\mathrm{pH}$ and ionic solutions we have focused on the region of near zero bias. The effect of changes in surface charge was modelled as an effective gate potential ( $\left.\mathrm{V}_{\mathrm{G}, \mathrm{eff}}\right)$, which was varied in the range from $-1.1 \mathrm{~V}$ to $0.2 \mathrm{~V}$ with $100 \mathrm{mV}$ steps and by specifying appropriate boundary conditions with surface pinning of $1.2 \mathrm{eV}$ for the range of different structures. The sensitivity is presented as the gain in carrier concentration calculated for first $100 \mathrm{mV}$ change in $\mathrm{V}_{\mathrm{G} \text {,eff }}$ from zero bias to allow direct comparison between structures with different composition. Also we have demonstrated the shift in optimal structure design as $\mathrm{V}_{\mathrm{G} \text {,eff }}$ moves from $0.2 \mathrm{~V}$ to $-1.1 \mathrm{~V}$.

\section{B. $p H$ Experiments with Modelled Structures}

In the experimental part of this work three Ga-face AlGaN/GaN heterostructures with $2 \mathrm{~nm}$ GaN cap with high predicted sensitivity according to the modelling were compared to three uncapped samples from previous work [14] with lower predicted sensitivity according to the modelling. In addition to covering a range of predicted sensitivities, the choice of heterostructures was influenced by material quality and processing difficulties which limited the upper range of AlGaN composition and lower range of AlGaN thickness. The list of the samples can be seen in Table II. Measurements were performed using four point bar mesa-etched test structure configurations (Fig. 1), with sensing areas $1.5 \mathrm{~mm}$ in diameter, $\mathrm{Al} / \mathrm{Cr} / \mathrm{Au}$ ohmic contacts, at constant currents of $100 \mu \mathrm{A}$ using 
a HP 4156A semiconductor parameter analyser. All measurements were performed under constant light conditions. Ungated devices fabricated on AlGaN/GaN HEMT wafers were exposed to different $\mathrm{KOH}$ solutions of $\mathrm{pH}$ from 8 to 12, and the potential drop across the gate area for constant current density was measured as a function of $\mathrm{KOH}$ concentration $(\mathrm{pH})$. Baked photo-resist and silicone gel were used for electrical isolation. Standard cleaning was applied to the AlGaN surface (acetone, isopropyl alcohol, de-ionised water and $\mathrm{N}_{2}$ blow-dry) after device fabrication, and ten second soak in $\mathrm{HCl}$ followed by rinsing in de-ionised water after exposure to each ionic solution. No other treatments were applied to the surface.

\section{RESULTS AND DISCUSSION}

\section{A. Theoretical Modelling of Sensitivity}

The main focus of the modelling is to predict experimentally measured gain in conductivity for variable AlGaN thickness and composition. While carrier concentration can be calculated theoretically at low computation time, mobility calculations are complex and computationally expensive. Therefore mobility data found in the literature was used for proof-of-concept purposes to show sensitivity can be predicted for a range of AlGaN thicknesses and compositions. Variation of 2DEG density, 2DEG mobility and 2DEG conductivity with $\mathrm{V}_{\mathrm{G} \text {,eff }}$ are shown for four different structures (Table I) in Figs. 2a, 3a and $4 \mathrm{a}$ respectively. Figs. $2 \mathrm{~b}, 3 \mathrm{~b}$ and $4 \mathrm{~b}$ demonstrate the variation in gain for the same parameters of modelled structures. As can be observed from the figures below both carrier concentration and mobility demonstrate maximum positive gain for near threshold values of $\mathrm{V}_{\mathrm{G} \text {,eff }}$ and so both will contribute to measured gain in conductivity.

It can be seen that gain in conductivity is maximum near threshold (structure A), but is not linear and can vary greatly as surface potential is varied on the order of volts. This is the main challenge for reference electrode free measurements. However, for careful heterostructure design and considering the very small potential influence of most chemical and biological compounds (on the order of tens of $\mathrm{mV}$ ) the gain will not change that much and the device will remain in the sensitive near-zero bias region, when designed with $\mathrm{V}_{\text {th }} \sim 0$. The maximum gain in conductivity is observed at near threshold voltage and can be calculated for any AlGaN thickness and composition using just carrier concentration.

Next the gain in carrier concentration was calculated for $-100 \mathrm{mV}$ change in $\mathrm{V}_{\mathrm{G} \text {,eff }}$ from zero bias to allow direct comparison of sensitivity between structures with different AlGaN composition and thickness. Results of these calculations can be found in Fig. 5

From Fig. 5 it can be concluded that the sensitivity is increased when the distance between surface and channel is reduced until depletion of the 2DEG results in a sharp threshold edge, the position of which also depends on the Al content. For thick barriers, changes in surface charge still modulate the amount of carriers in the channel, but the relative change reflected in the sensitivity is small because of the higher carrier concentrations. The sensitivity of the most promising structures is in the range of $20 \mathrm{~dB}$ at near zero bias and will decrease as surface potential becomes more negative. Structures with less than optimal design will have lower sensitivity at near zero gate bias. However, sensitivity of non-optimal structures can increase as surface potential becomes more negative and the sensitivity of the optimal structure will decrease. This effect is partly demonstrated in Fig. 6 where we plotted thresholds that are close to applied surface potential and therefore the shift in optimal structures can be observed as surface potential changes from -1.1 to $0.2 \mathrm{~V}$. As threshold value stays constant for a given AlGaN thickness and composition the shift observed in Fig. 6 demonstrates what changes should be introduced to AlGaN thickness and composition to optimise sensitivity when surface potential is likely to be shifted to more negative or more positive values (shifted away from zero bias). Also the increase and decrease in sensitivity for a given structure can be predicted through such diagrams and be used for calibration and signal analyses. In the case of more negative surface potential the shift in the optimal structure design, to keep sensitivity at around $20 \mathrm{~dB}$, should be towards slightly thicker structures with more negative thresholds. However, we are still looking at a rather narrow region of thicknesses and compositions. Therefore a combination approach can be used with the calculations, by designing an optimised device and then calibrating for changes in surface potential.

\section{B. $p H$ Experiments with Modelled Structures}

All six devices with different predicted sensitivity were exposed to $\mathrm{KOH}$ solutions of different $\mathrm{pH}$ values and the data obtained were normalised to the maximum potential drop that was observed for $\mathrm{KOH}$ with $\mathrm{pH} 12$ for each device. Fig. 7 shows as-measured data for the sample 2 device which in Fig. 5 lay in the region that was predicted to be close to maximum sensitivity.

The response to different $\mathrm{KOH}$ solutions for all six ungated AlGaN/GaN HEMT-based devices, normalised to the maximum response for each device ( $\mathrm{pH} 12$ ), is given in Fig. 8. The sensitivity values calculated from experimental data in terms of overall gain in conductivity from $\mathrm{pH} 8$ to $\mathrm{pH} 12$ for all devices are summarised in Table II and can be compared to Fig. 5. It can be seen that the results obtained in the experimental part of this work demonstrate significant correlation with predicted sensitivity. Moreover, from the normalised data it can be seen that the increase in measured voltage is not linear; the shape is directly related to the exponential change in $\mathrm{KOH}$ concentration with $\mathrm{pH}$ for most of the devices. However, the sample 1 device has a slightly different shape due to the fact that sensitivity itself is changing with $\mathrm{KOH}$ concentration, corresponding to the change in sensitivity with $\mathrm{V}_{\mathrm{G} \text {,eff }}$ surface potential (see Figs. 5 and 6).

\section{CONCLUSION}

In this paper we report on a methodology for quick and simple prediction and optimization of AlGaN/GaN device sensitivity operated in reference electrode free configuration desirable for miniaturised sensors. We have demonstrated that by optimisation of the AlGaN layer (composition and 
thickness), the sensitivity of reference-electrode-free AlGaN/GaN heterostructure-based ion sensors can be dramatically improved. A model was applied to estimate the sensitivity of different structures and showed sensitivity can be maximised by designing a structure to have near-zero threshold voltage. One example of an ISFET device with maximal sensitivity is demonstrated. However there are many other heterostructure designs that would produce similar sensitivity. In particular, due to practical limitations high- $\mathrm{x}_{\mathrm{Al}}$ or $\mathrm{x}_{\mathrm{Al}}=1$ (AlN/GaN) structures were not experimentally investigated in this work but are certainly indicated to be highly sensitive for very thin $\mathrm{Al}(\mathrm{Ga}) \mathrm{N}$ layers. Future improvements in this technology could include investigation of thin AlN layer devices with low threshold voltage. The model allows selection of appropriate design taking into account other factors such as complementary devices, material quality, or processing issues that may influence selection of specific AlGaN composition or thickness. Experimental results confirmed the predictions of the model, with high signal to noise ratio and gain in conductivity with $\mathrm{KOH}$ exposure for the devices grown on the structures with near zero thresholds. These results can be used to improve performance for future chemical and biochemical sensors 


\section{REFERENCES}

[1] Y.-W. Kang, G.-Y.Lee, J.-I.Chyi, C.-P.Hsu, Y.-R.Hsu, C.-C.Huang, F. Ren, and Y.-L. Wang, "A Novel Detection of Non-Nucleoside Reverse Transcriptase Inhibitors (NNRTIs) for HIV-1 with AlGaN/GaN High Electron Mobility Transistors,” ECS Trans., vol. 53, no. 2, pp. 55-59, May 2013.

[2] B. Kang, S. J. Pearton, J. J. Chen, F. Ren, J. W. Johnson, R. J. Therrien, P. Rajagopal, J. C. Roberts, E. L. Piner, and K. J. Linthicum, "Electrical Detection of Deoxyribonucleic Acid Hybridization With AlGaN/GaN High Electron Mobility Transistors,” MRS Online Proc. Libr., vol. 955, 2006.

[3] A. Podolska, L. C. Hool, K. D. G. Pfleger, U. K. Mishra, G. Parish, and B. D. Nener, "AlGaN/GaN-based biosensor for label-free detection of biological activity,” Sensors Actuators B Chem., vol. 177, pp.577-582, Feb. 2013.

[4] G. Steinhoff, M. Hermann, W. J. Schaff, L. F. Eastman, M. Stutzmann, and M. Eickhoff, "pH response of $\mathrm{GaN}$ surfaces and its application for pH-sensitive field-effect transistors,” Appl. Phys. Lett., vol. 83, no. 1, pp. 177-179, Jul. 2003.

[5] M. Stutzmann, G. Steinhoff, M. Eickhoff, O. Ambacher, C. E. Nebel, J. Schalwig, R. Neuberger, and G. Müller, "GaN-based heterostructures for sensor applications,” Diam. Relat. Mater., vol. 11, no. 3-6, pp. 886-891, Mar. 2002.

[6] O. Ambacher, J. Smart, J. R. Shealy, N. G. Weimann, K. Chu, M. Murphy, W. J. Schaff, L. F. Eastman, R. Dimitrov, L. Wittmer, M. Stutzmann, W. Rieger, and J. Hilsenbeck, "Two-dimensional electron gases induced by spontaneous and piezoelectric polarization charges in N- and Ga-face AlGaN/GaNheterostructures,” J. Appl. Phys., vol. 85, no. 6, pp. $3222-$ 3233, Mar. 1999.

[7] B. S. Kang, H. T. Wang, F. Ren, B. P. Gila, C. R. Abernathy, S. J. Pearton, D. M. Dennis, J. W. Johnson, P. Rajagopal, J. C. Roberts, E. L. Piner, and K. J. Linthicum, "Exhaled-Breath Detection Using AlGaN / GaN High Electron Mobility Transistors Integrated with a Peltier Element," Electrochem. Solid-State Lett., vol. 11, no. 3, pp. J19-J21, Mar. 2008.

[8] B. S. Kang, H. T. Wang, T. P. Lele, Y. Tseng, F. Ren, S. J. Pearton, J. W. Johnson, P. Rajagopal, J. C. Roberts, E. L. Piner, and K. J. Linthicum, "Prostate specific antigen detection using AlGaN/GaN high electron mobility transistors," Appl. Phys. Lett., vol. 91, no. 11, pp. 112106112106-3, Sep. 2007.

[9] B. S. Kang, H. T. Wang, F. Ren, B. P. Gila, C. R. Abernathy, S. J. Pearton, J. W. Johnson, P. Rajagopal, J. C. Roberts, E. L. Piner, and K. J. Linthicum, "pH sensor using AlGaN/GaN high electron mobility transistors with Sc2O3 in the gate region “, Appl. Phys. Lett. 91, 012110, 2007.

[10] B.S. Kang, F. Ren, M.C. Kang, C. Lofton, Weihong Tan, S.J.Pearton, A. Dabiran, A. Osinsky, and P.P. Chow, "Detection of halide ions with AlGaN/GaN high electron mobility transistors”, Appl. Phys. Lett. 86, 173502, 2005.

[11] S.C.Hung, B.Hicks, Y.L.Wang, S.J.Pearton, D.M.Dennis, F.Ren, J. W. Johnson, P.Rajagopal, J.C.Roberts, E.L.Piner, K.J.Linthicum and G.C.Chi, "Detection of Cl- Ions Using Integrated Ag/AgCl Electrode with AlGaN/GaN HEMTs”, Appl.Phys. Lett., 92, 193903, 2008.

[12] A. B. Encabo, J. Howgate, M. Stutzmann, M. Eickhoff, and M. A. Sánchez-García, "Ultrathin GaN/AlN/GaN solution-gate field effect transistor with enhanced resolution at low source-gate voltage," Sensors Actuators B Chem., vol. 142, no. 1, pp. 304-307, 2009.

[13] T. Brazzini, A. Bengoechea-Encabo, M. A. Sánchez-García, and F. Calle, "Investigation of AlInN barrier ISFET structures with GaN capping for pH detection," Sensors Actuators B Chem., vol. 176, pp. 704-707, Jan. 2013.

[14] A. Podolska, M. Kocan, A. M. G. Cabezas, T. D. Wilson, G. A. UmanaMembreno, B. D. Nener, G. Parish, S. Keller, and U. K. Mishra, "Ion versus $\mathrm{pH}$ sensitivity of ungated $\mathrm{AlGaN} / \mathrm{GaN}$ heterostructure-based devices," Appl. Phys. Lett., vol. 97, no. 1, pp. 012108-012108-3, Jul. 2010.

[15] S. Rabbaa and J. Stiens, "Validation of a triangular quantum well model for GaN-based HEMTs used in $\mathrm{pH}$ and dipole moment sensing," J. Phys. Appl. Phys., vol. 45, no. 47, p. 475101, Nov. 2012.

[16] P. Bergveld, "Thirty years of ISFETOLOGY: What happened in the past 30 years and what may happen in the next 30 years," Sensors Actuators $B$ Chem., vol. 88, no. 1, pp. 1-20, Jan. 2003.

[17] M. Myers, F. L. M. Khir, A. Podolska, G. A. Umana-Membreno, B. Nener, M. Baker, and G. Parish, "Nitrate ion detection using AlGaN/GaN heterostructure-based devices without a reference electrode," Sensors Actuators B Chem., vol. 181, pp. 301-305, May 2013.

[18] A. Asgari and M. Kalafi, "The control of two-dimensional-electron-gas density and mobility in AlGaN/GaN heterostructures with Schottky gate," Mater. Sci. Eng. C, vol. 26, no. 5-7, pp. 898-901, Jul. 2006.

[19] T. N. Upal, M. A. Uddin, M. Hossain, F. Jahan, and Z. H. Mahmood, "Study of charge density at $\operatorname{In}_{\mathrm{x}} \mathrm{Ga}_{1-\mathrm{x}} \mathrm{N} / \mathrm{GaN}$ heterostructure interface," in 2nd International Workshop on Electron Devices and Semiconductor Technology, 2009. IEDST '09, 2009, pp. 1-4.

Anna Podolska received the $\mathrm{PhD}$ in engineering (sensor micro-electronics) from the University of Western Australia in 2014. Prior to this she obtained the Bachelor of Engineering in physical electronics from Kyiv Polytechnic Institute in Ukraine.

She first worked as a research associate developing solid state sensors based on semiconductor electronic devices, and then won a prestigious William and Marlene Schrader Postgraduate Scholarship (Biomedical Engineering) to conduct postgraduate study at the University of Western Australia in 2010. During her $\mathrm{PhD}$ work she collaborated with many research institutions in Australia and overseas. In the last quarter of her $\mathrm{PhD}$ degree studies she joined the sensors group at CSIRO to participate in developing optical fibre based sensors for downhole hydrocarbon detection. Upon graduation she joined the Department of Exploration Geophysics at Curtin University to pursue her interest in developing novel sensors for the earth sciences.

Daniel Broxtermann received the diploma and $\mathrm{PhD}$ degree in Physics at the Georg-August-Universty Goettingen in 2007 and 2011, respectively.

His research was focussed on the epitaxial growth of GaNbased heterostructures and on electrical transport in lowdimensional systems. In 2012 he joined Infineon and started a career in industry.

Joerg Malindretos received the diploma in Physics at the University of Aachen in 1998 and the PhD degree at Research Center Juelich in 2001.

Subsequently he spent one year as a PostDoc at Arizona State University, Phoenix. Since 2004 he is scientific staff member at Georg-August-Universty Goettingen. His main research interests are concerned with new functionalities of group III-N based hetero- and nanostructures: GaN/InGaN nanocolumns for solid-state lighting, two-dimensional electron gases for sensor applications as well as GaN-based dilute magnetic semiconductors and hybride structures for spin-injection.

Gilberto A. Umana-Membreno (S'93-M'07) received his $\mathrm{PhD}$ in Electrical and Electronic Engineering from the University of Western Australia (UWA) in 2007

He currently holds a senior research appointment at UWA with the Microelectronics Research Group (MRG). His research activities include characterization and modelling of electronic transport and defect-related effects in semiconductor materials, and in the optimisation electronic and optoelectronic semiconductor devices. At the MRG, his current research interests are in the development and optimisation of practical devices in $\mathrm{HgCdTe}$, InAs/InGaSb and III-nitrides, as well as in the investigation of electronic processes in high-k dielectrics and in semiconductor-based micro-electro-mechanical systems. 
Stacia Keller received the Diploma and Ph.D. degree in chemistry from the University of Leipzig, Germany, in 1983 and 1986, respectively.

In 1994, she joined the Electrical and Computer Engineering Department, University of California at Santa Barbara. Her research interests include crystal growth and characterization of group-III nitrides, as well as nitride based electronic and optoelectronic devices. She has authored or co-authored over 400 technical publications and holds 16 US patents.

Umesh K. Mishra (F'95) received the Bachelor of Technology degree from the Indian Institute of Technology, Kanpur, India, the Master's degree from Lehigh University, Bethlehem, PA, and the Ph.D. degree from Cornell University, Ithaca, N.Y., all in electrical engineering.

He is currently a Professor of electrical and computer engineering with the University of California at Santa Barbara (UCSB). A recognized leader in the area of high-speed fieldeffect transistors, he has made major contributions at every laboratory and academic institution for which he has worked, including North Carolina State University, Raleigh, Hughes Research Laboratories, Malibu, CA, The University of Michigan at Ann Arbor, and General Electric, Syracuse, NY. He cofounded Wi-Tech (later Nitres), which was acquired by Cree Inc, to commercialize both GaN-based laser-emitting diodes (LEDs) and transistors in 1996, and co-founded Transphorm in 2007, to commercialize GaN-based power systems. Transphorm was selected as a World Economic Forum 2013 Technology Pioneer. He has authored or coauthored over 900 papers and holds numerous patents in the area of compound semiconductors.

Prof. Mishra was the recipient of numerous awards, including the 2007 IEEE David Sarnoff Technical Field Award for development of GaN electronics. In 2009, he was elected to the National Academy of Engineering in recognition of his contributions to the development of GaN electronics and other high-speed high-power semiconductor electronic devices.

Angela Rizzi received the Laurea in Physics at the University of Modena, Italy and in 1987 the PhD degree in Physics at the Politecnico di Milano, Italy.

She is currently Professor for Experimental Physics at the Georg-August University Goettingen, where she has been since 2002. From 1988-1989 she was Humboldt-Research fellow at the RWTH Aachen and at the Research Center Juelich. From 1990 until 2002 she held a Researcher staff position at the University of Modena, Italy. She is presently Coordinator of the FP7 EU “nanowiring” network for initial training 265073. Her main experience is in Physics of semiconductor hetero- and nanostructures and Molecular Beam Epitaxy of group III-N nitrides with focus on the structural, electronic and optical properties. In particular, in recent times group-III-N nanocolumns for solid-state lighting and magnetic metal/semiconductor structures for spin-injection.

Brett D. Nener (S'78-SM'93) received the B.E. and Ph.D. degrees from The University of Western Australia, and the M.Sc. from the University of Tokyo.
He is a Professor in the School of Electrical, Electronic and Computer Engineering at The University of Western Australia where he was the Head of School 2008-2014. He has been a Visiting Professor to the U.S. Navy Space and Naval Warfare Center, San Diego, CA and the University of California, Santa Barbara. His current areas of research interest are biosensors; III-N devices; modeling of atmospheric effects such as refraction, scintillation and aerosol scattering.

Giacinta Parish (S'97-M’01) received the B.S. degree in Chemistry in 1995, and the B.E. and M.Eng.Sc degrees in electronic engineering in 1995 and 1997, respectively, all from The University of Western Australia, Perth, and the Ph.D. degree in electrical engineering in 2001, from the University of California, Santa Barbara.

She joined The University of Western Australia as an Australian Postdoctoral Fellow in 2001, and is now an Associate Professor at the same institution. Her main research interests are III-V nitride materials and devices, and more recently porous silicon. Specific interests within these areas currently include development of processing technology, transport studies, and development of novel chem- and biosensors. 
TABLE I

ALGAN/GAN STRUCTURES USED FOR SIMULATION

\begin{tabular}{|c|c|c|c|}
\hline Structure & $\begin{array}{c}\text { Al mole } \\
\text { fraction (\%) }\end{array}$ & $\begin{array}{c}\text { AlGaN thickness } \\
(\mathrm{nm})\end{array}$ & $\begin{array}{c}\text { Threshold } \\
\text { Voltage (V) }\end{array}$ \\
\hline A & 22 & 20 & -3.5 \\
\hline B & 22 & 24 & -5 \\
\hline C & 25 & 35 & -9 \\
\hline D & 30 & 35 & -10.5 \\
\hline
\end{tabular}

TABLE II

SumMARY OF DifFERENT SAMPLE STRUCTURES WiTH MEASURED HALL DATA AND EXPERIMENTALLY OBTAINED SENSITIVITY.

\begin{tabular}{|c|c|c|c|c|c|}
\hline $\begin{array}{l}\text { Sample } \\
\text { ID }\end{array}$ & $\begin{array}{l}\text { Growth } \\
\text { method }\end{array}$ & Structure & $\begin{array}{c}\mathrm{n}_{\mathrm{s}} \\
{\left[\mathrm{cm}^{-2}\right]}\end{array}$ & $\begin{array}{c}\mu \\
{\left[\mathrm{cm}^{2} \mathrm{~V}^{-1} \mathrm{~s}^{-1}\right]}\end{array}$ & $\begin{array}{c}\text { Sensitivity } \\
{[\mathrm{dB}] \text { (Gain }} \\
\text { from pH8 to } \\
\mathrm{pH} 12 \text { ) }\end{array}$ \\
\hline 1 & MOCVD & $\begin{array}{c}12 \mathrm{~nm} \mathrm{Al} \mathrm{Al}_{0.23} \mathrm{Ga}_{0.77} \mathrm{~N} \text { with } \\
2 \mathrm{~nm} \mathrm{GaN} \mathrm{cap}\end{array}$ & $5.09 \times 10^{12}$ & 1785 & -4.9 \\
\hline 2 & MBE & $\begin{array}{c}10 \mathrm{~nm} \mathrm{Al}_{0.3} \mathrm{Ga}_{0.7} \mathrm{~N} \text { with } \\
2 \mathrm{~nm} \mathrm{GaN} \mathrm{cap}\end{array}$ & $6.34 \times 10^{12}$ & 856 & -7.8 \\
\hline 3 & MBE & $\begin{array}{l}\text { 20nm Al } \mathrm{Al}_{0.2} \mathrm{Ga}_{0.8} \mathrm{~N} \text { with } \\
\text { 2nm GaN cap }\end{array}$ & $5.15 \times 10^{12}$ & 1101 & -17.7 \\
\hline 4 & MOCVD & $\begin{array}{l}29 \mathrm{~nm} \mathrm{Al}_{0.15} \mathrm{Ga}_{0.85} \mathrm{~N} \\
\text { (with AlN interlayer) }\end{array}$ & $3.78 \times 10^{12}$ & 2093 & -26.5 \\
\hline 5 & MOCVD & $\begin{array}{l}23 \mathrm{~nm} \mathrm{Al}_{0.23} \mathrm{Ga}_{0.77} \mathrm{~N} \\
\text { (with AlN interlayer) }\end{array}$ & $6.53 \times 10^{12}$ & 2254 & -34.8 \\
\hline 6 & MOCVD & $\begin{array}{l}22 \mathrm{~nm} \mathrm{Al}_{0.29} \mathrm{Ga}_{0.71} \mathrm{~N} \\
\text { (with AlN interlayer) }\end{array}$ & $7.34 \times 10^{12}$ & 2230 & -44.7 \\
\hline
\end{tabular}




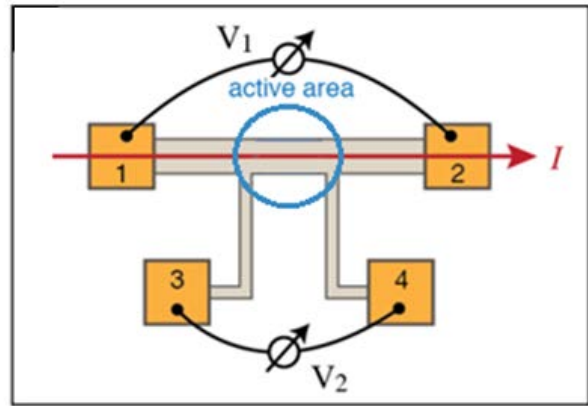

Fig. 1. Measurement configuration for Kelvin probe measurement with four ohmic contact pads on mesa-etch structure.

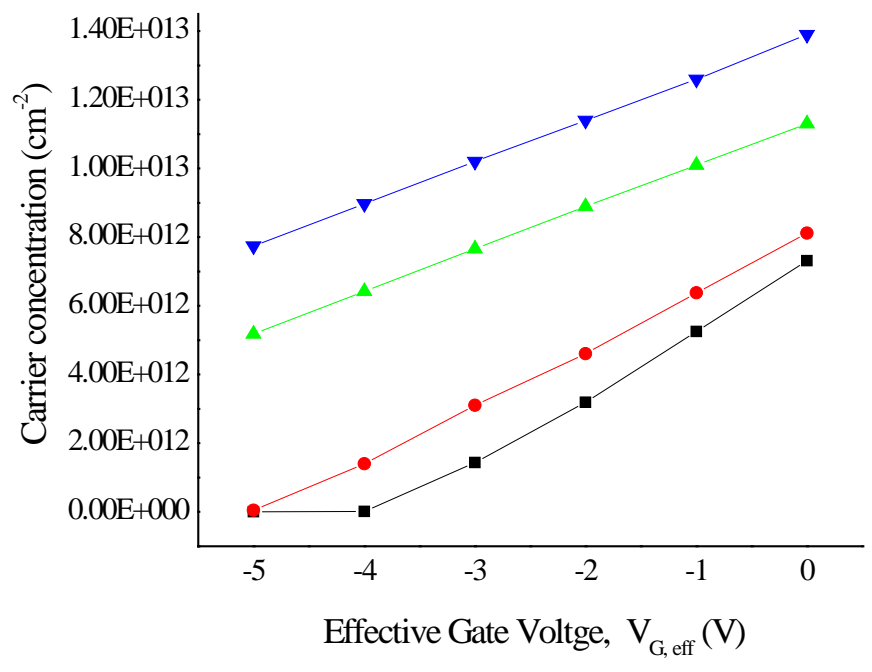

(a)

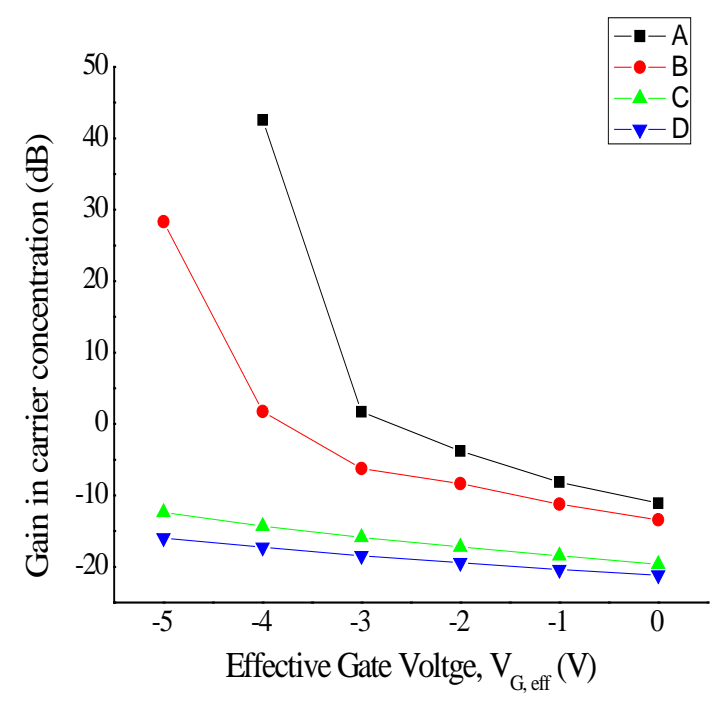

(b)

Fig. 2. (a) Variation of carrier concentration with gate bias and (b) variation of gain in carrier concentration with gate bias (for step of $1 \mathrm{~V}$ ) calculated according to equation 1 , for four different structures described in Table I. 


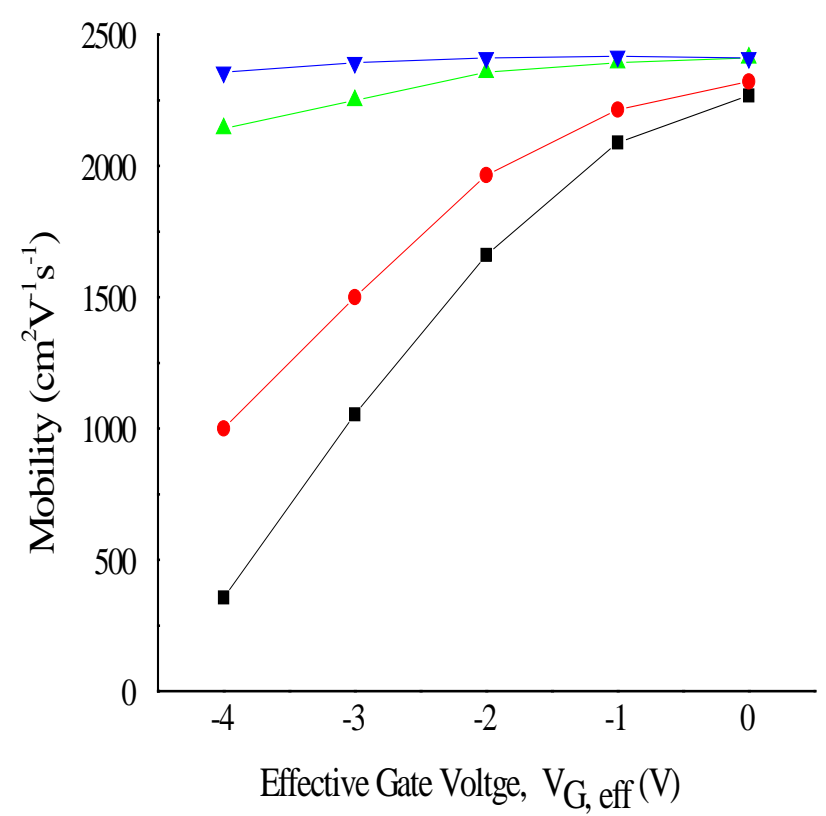

(a)

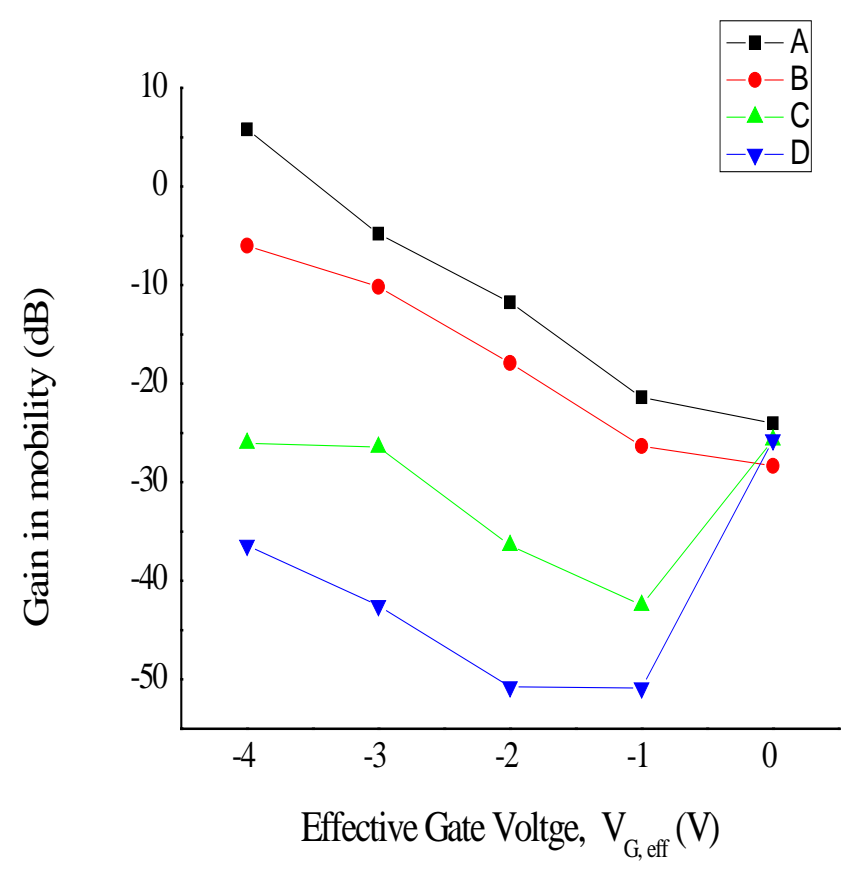

(b)

Fig. 3. (a) Variation of carrier mobility with gate bias and (b) variation of gain in carrier mobility with gate bias (for step of $1 \mathrm{~V}$ ) according to equation 1 , for four different structures described in Table I.

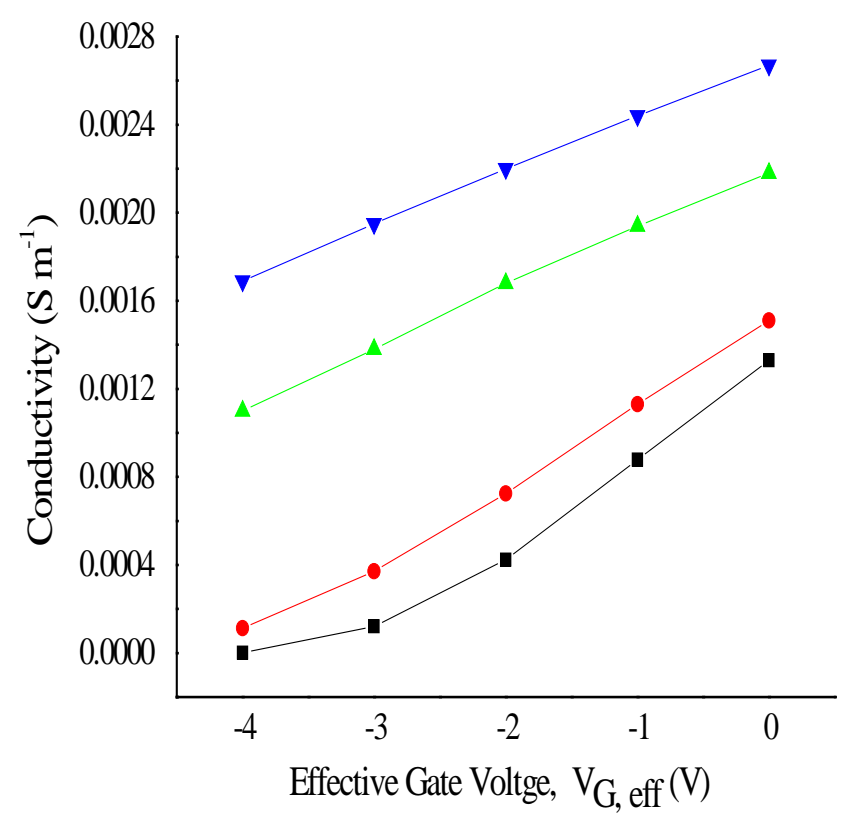

(a)

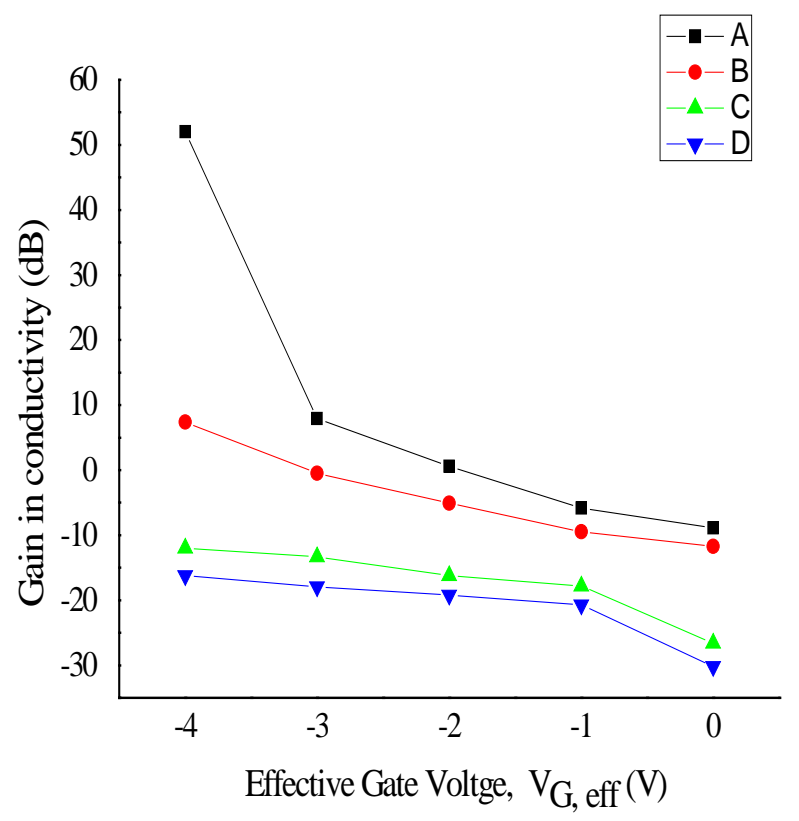

(b)

Fig. 4. (a) Variation of conductivity for variable gate bias and (b) variation of gain in conductivity for variable gate bias (for step of $1 \mathrm{~V}$ ) calculated according to equation 1 and 2, for four different structures described in Table I. 


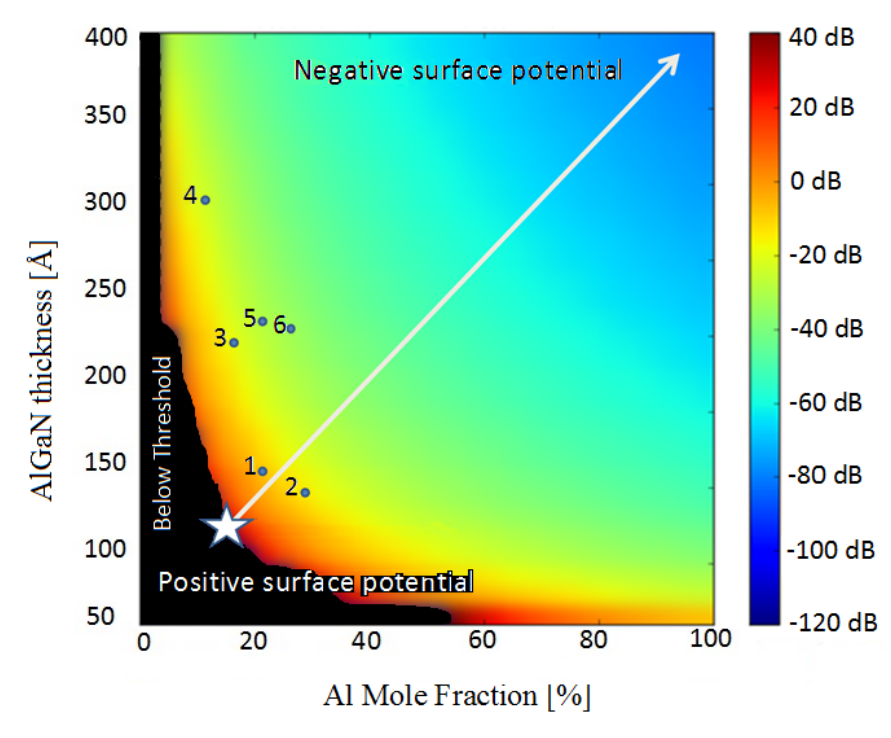

Fig. 5. Contour plot of the calculated sensitivity in terms of Gain=20 log $(\Delta \mathrm{ns} / \mathrm{ns})[\mathrm{dB}]$ for a change in zero surface potential of $-100 \mathrm{mV}$ for ungated AlGaN/GaN devices with a $2 \mathrm{~nm} \mathrm{GaN} \mathrm{cap} \mathrm{layer.} \mathrm{Numbers} \mathrm{from} 1$ to 6 correspond to sample IDs in Table II.

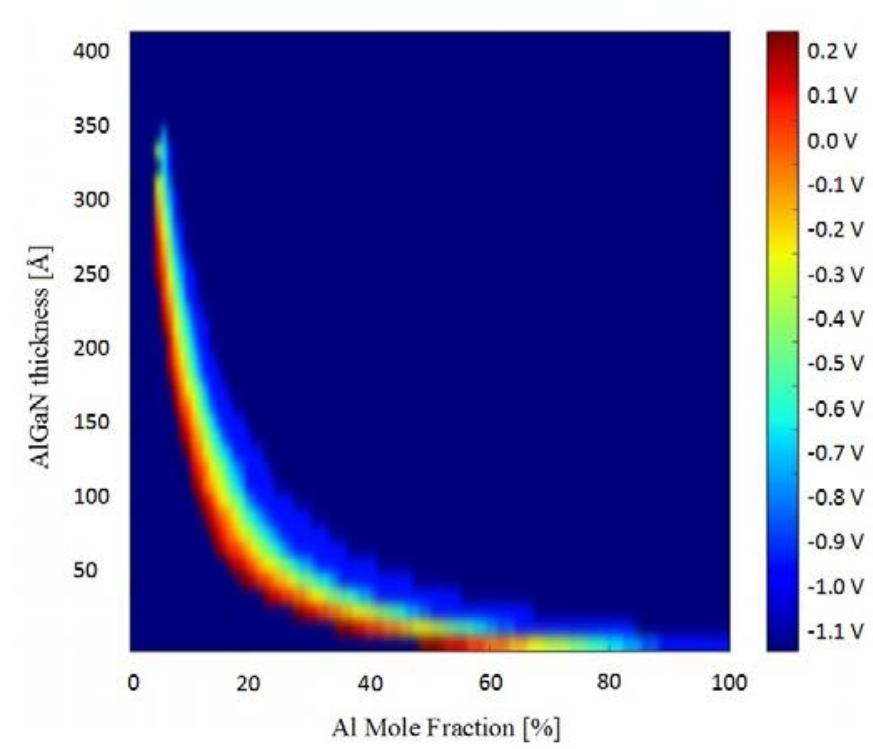

Fig. 6.Contour plot of thresholds near different surface potentials varied from 1.1 to $0.2 \mathrm{~V}$ with $-100 \mathrm{mV}$ step for the range of $\mathrm{Al}_{1-\mathrm{x}} \mathrm{Ga}_{\mathrm{x}} \mathrm{N} / \mathrm{GaN}$ structures.

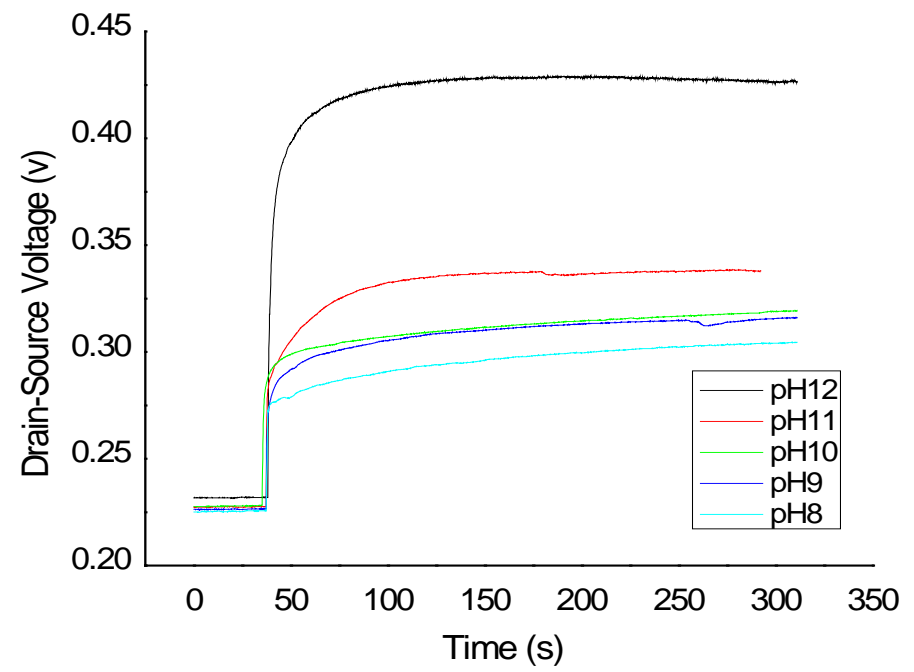

Fig. 7. Response to $\mathrm{KOH}$ solutions of sample 2 measured as change in voltage for fixed current. For each voltage curve, the point at which the voltage sharply increases corresponds to the point at which the $\mathrm{KOH}$ solution was applied.

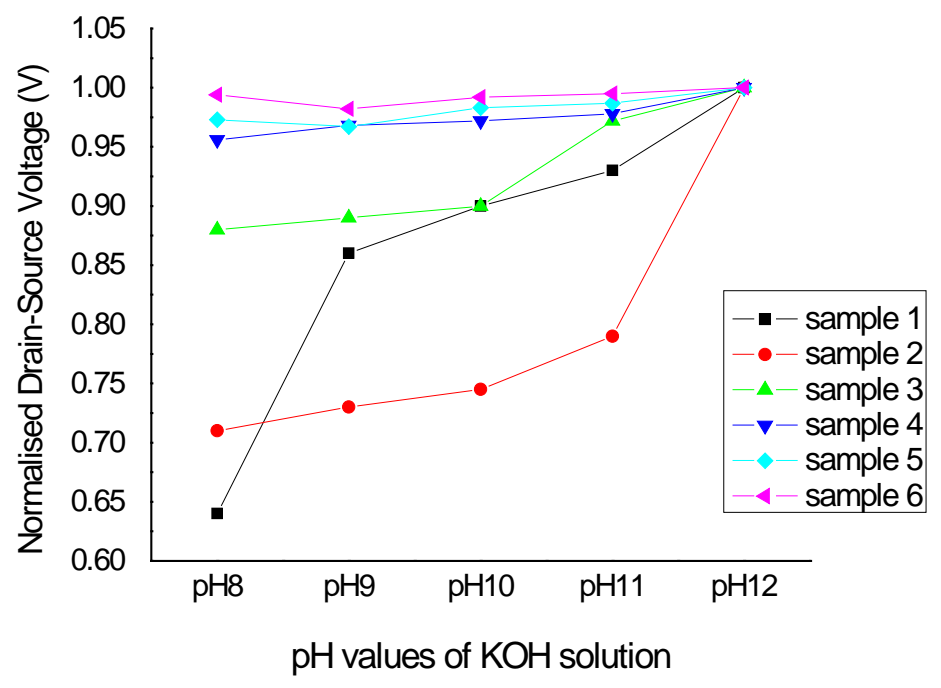

Fig. 8. Maximum potential drop for six ungated AlGaN/GaN HEMT-based devices exposed to different $\mathrm{KOH}$ solutions (normalised to the value obtained for $\mathrm{pH} 12$ for each device). 